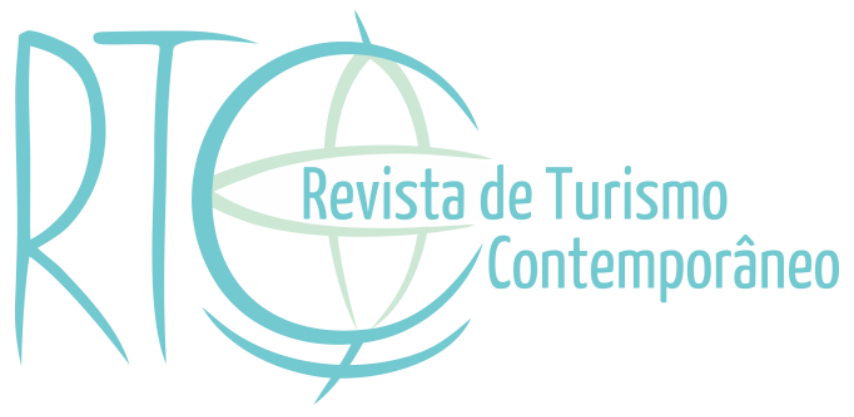

\title{
A política pública de turismo da Embratur e suas transformações até a atualidade
}

Embratur's public policy on tourism and its transformations so far

Livia Cristina Barros da Silva Wiesinieski

Doutoranda do Programa de Pós Graduação em Arquitetura e Urbanismo da Universidade de Brasília - UnB, Brasília/DF, Brasil

E-mail: liviabsw@gmail.com

Paula Schulz dos Santos

Graduanda em Turismo da Universidade de Brasília - UnB, Brasília/DF, Brasil

E-mail: pschulz.santos@gmail.com

Artigo recebido em: 01-12-2020

Artigo aprovado em: 01-06-2021 


\section{RESUMO}

Dado o papel chave que a Embratur - Agência Brasileira de Promoção Internacional do Turismo tem no turismo nacional, sendo o órgão mais antigo do tipo em atividade, o presente trabalho propôs-se a estudar, de maneira qualitativa e exploratória, a construção de políticas públicas desde sua criação até os dias atuais, analisando as estratégias de promoção do Brasil no exterior. Para isso, realizou-se a análise documental da legislação, planos, programas e ações do órgão de 1966 a 2019. Os resultados foram analisados a partir das perspectivas de pesquisa avaliativa e análise de conteúdo, apontando para questões-chave a serem abordadas a partir de sua mudança de natureza jurídica ocorrida em 2020. As questões-chave são: a marca país; o regime de contratações; o acesso à recursos financeiros e tecnologias para melhor aproveitar os bens turísticos nacionais; a compreensão de sua própria história, a fim de evitar cometer novamente os erros do passado, como a não observação às tendências mundiais em promoção, utilização de linguagem de promoção com conotação sexual (desde as revistas dos anos 70 até o slogan "Brazil, visit and love us" e a falta de política norteadora clara para execução de suas ações.

Palavras-chave: Política de incentivo ao Turismo. Embratur. Estratégias de Marketing. Política Pública. Organismos de Turismo.

\section{ABSTRACT}

Given the key role that Embratur - Agência Brasileira de Promoção Internacional do turismo, has in national tourism, being the oldest organ of the type in activity, the present work proposed to study, in a qualitative and exploratory way the construction of policies from its creation to the present day. To this end, a documentary analysis of the legislation, plans, programs and actions of the agency was carried out from 1964 to 2019. Thus, the results were analyzed from the perspectives of evaluative research and content analysis, pointing to key issues to be addressed from its change of legal nature, which occurred in 2020. These are: the country brand, the hiring regime, access to financial resources and technologies to better take advantage of national tourism assets and, above all, the understanding of its own history in order to avoid making the mistakes of the past again, such as the failure to observe global trends in promotion, the use of promotional language with sexual connotations (from the magazines of the 70s to the slogan "Brazil, visit and love us") and the lack of a clear guiding policy for carrying out their actions.

Keywords: Tourism incentive policies. Embratur. Marketing strategies. Public Policy. Tourism agencies. 


\section{INTRODUÇÃO}

Em 2020 o mundo foi surpreendido pela pandemia de COVID-19. Em novembro a Ásia, Europa e as Américas enfrentavam a segunda onda de contaminação alcançando 61.026.993 casos e 1.432.817 mortes (Covid-19 Visualizer, 2020). No mesmo período, o Brasil reportava 6.204.220 casos da doença e 171.460 mortos (Covid-19 Visualizer, 2020). Este cenário repercutiu na dinâmica do turismo, tanto em função do fechamento de fronteiras, quanto na suspensão das atividades não essenciais e alteração nas políticas trabalhistas e de apoio ao prestador de serviços (Brasil, 2020a; Brasil, 2020b).

Para a Academia, a pandemia oportunizou a mudança de paradigma e demonstrou a fragilidade das previsões e cenarizações para o turismo, que passa a ser entendido como "Uma atividade que nem sempre é valorizada pelos setores sociais como atividade econômica, social, cultural e como área de estudos, mas quando é impedida de ser realizada, sentimos sua ausência, daí que ela evidencia seu poder" (Panosso Netto, Oliveira, \& Severini, 2020, p. 19).

As incertezas experienciadas pelo setor alertam sobre a oportunidade de transformação do planejamento e gestão do turismo, priorizando suas implicações socioculturais e econômicas a partir do apoio e orientação dos organismos de turismo como a Organização Mundial do Turismo (OMT), Ministério do Turismo (MTur) e a EMBRATUR (Agência Brasileira de Promoção Internacional do Turismo) na busca de diretrizes norteadoras capazes de sensibilizar e minimizar a insegurança dos turistas.

Como medida emergencial, o MTur dedicou-se na promoção da campanha "Não cancele, remarque" (Brasil, 2020c) e do programa "Selo Turismo Responsável” (Brasil, 2020c). Neste período a Agência Brasileira de Promoção Internacional do Turismo - EMBRATUR, ainda em processo de reestruturação, acompanhou e apoiou a atuação ministerial, tendo sido proibida pelo Art. 34 da Lei que a criou, de realizar ações voltadas ao turismo internacional, conforme o texto,

\footnotetext{
Desde a decretação do estado de emergência até 6 (seis) meses após a superação das circunstâncias que o originaram, a utilização de recursos da Embratur para promoção do turismo será direcionada exclusivamente para o turismo doméstico, inclusive mediante a celebração de convênios com os Estados, o Distrito Federal e os Municípios, sob a coordenação do Ministério do Turismo (Brasil, 2020d).
}

As turbulências enfrentadas pela crise sanitária coincidem com o processo de recondução e transformação da EMBRATUR com a extinção do Instituto Brasileiro de Turismo e a criação da Agência Brasileira de Promoção Internacional do Turismo garantindo sua competência de promoção, divulgação e apoio a comercialização do turismo Brasileiro. 
Entendendo o contexto de transformação como oportunidade de aprendizado, acreditase na relevância de retornar à história da EMBRATUR e (re) conhecer sua trajetória na comunicação e imagem do Brasil, assim como visualizar os efeitos de sua atuação no incremento do fluxo turístico brasileiro. Portanto, este artigo tem como objetivo analisar as estratégias de promoção do Brasil no exterior a partir do mapeamento dos planos, programas e ações realizados pela Agência Brasileira de Promoção Internacional do Turismo (EMBRATUR).

A metodologia utilizada na pesquisa é de caráter qualitativo e exploratório a partir de levantamento bibliográfico em fontes primárias e secundárias para construção do cenário estudado. Para interpretação dos dados, utilizou-se da análise documental de legislação, ações, planos e programas de turismo, junto à Pesquisa Avaliativa e Análise de Conteúdo (Vasconcelos, 2002), que permitiram estabelecer correlações entre as ações desenvolvidas e a variação do fluxo de turistas disponibilizado pelos Anuários Estatísticos de Turismo do Ministério do Turismo nos anos de 2005, 2006, 2008-2012 e 2014-2019.

Apresenta-se como resultado a trajetória da EMBRATUR e os efeitos das políticas públicas aplicadas pelo organismo durante seus 54 anos de atuação, seja como Empresa, Instituto ou, mais recentemente, como Agência de promoção.

\section{POLÍTICA PÚBLICA E SEU PAPEL NO TURISMO}

Política Pública, segundo Peters (1986 como citado em Souza, 2006, p. 24), se caracteriza como a soma das atividades dos governos, que agem diretamente ou através de delegação, e que influenciam a vida dos cidadãos. Pode-se entender o governo como uma organização específica de poder a serviço do Estado por um determinado período de tempo. Por sua vez, entende-se que o Estado se refere à totalidade da sociedade política, ou seja, o conjunto de pessoas e instituições que formam a sociedade juridicamente organizada sobre um determinado território.

Portanto, busca suprir os interesses do governo, que exerce sua influência e poder sobre o Estado e tudo que o compõe. Neste contexto a sociedade torna-se foco das ações e razão de ser da política pública. Desde a redemocratização e a promulgação da Constituição Federal de 1988, seu papel é de pressão no governo, por meio da participação democrática.

A política pública de turismo (PPT) compreende o direcionamento dado pelo governo federal, estadual ou municipal para o desenvolvimento da atividade turística após consulta aos representantes do setor turístico e da sociedade (Lohmann \& Panosso Netto, 2008). Dentro 
dessa afirmação, é possível interpretar que seu processo de formação exige um esforço coletivo que abrange diferentes setores da sociedade e o governo.

Schenkel (2018) sumariza dizendo que

\begin{abstract}
Em princípio, pode-se dizer que a política de turismo é a atuação da ação pública em relação ao turismo. Isso implica o que o governo decide fazer ou não fazer em relação específica ao setor (Hall 2010, como citado em Schenkel, 2018). O termo 'específico' é enfatizado para diferenciar a política de turismo de outras, que podem ter um impacto sobre o turismo, mas não são desenvolvidas como políticas de turismo per se (tradução nossa) ${ }^{1}$.
\end{abstract}

Historicamente, a PPT, percorreu três fases (Pimentel, M. P., Pereira, Pimentel, T., \& Carrieri, 2011, p. 7): Turismo Fordista, entre 1930 e 1945; Turismo Responsável, a partir de 1970 e o Turismo Competitivo, a partir de 1980. A era Fordista inicia-se com o estímulo ao turismo de massa, focados em resultados quantitativos, desconsiderando os efeitos qualitativos nos campos socioeconômicos e ambientais caminhando para reestruturação e construção do Turismo Responsável. Esta fase centra-se nos residentes das destinações, o que minimizou os impactos negativos do turismo, mas reduziu seus reflexos positivos, destacando a necessidade de repensar a atuação e promover a competitividade.

Hoje, há uma necessidade latente de PPTs para manutenção das atividades turísticas no Brasil, tendo em vista que a pandemia impactou profundamente o mercado de viagens e lazer. Já existem ações pontuais do Ministério do Turismo para isso, como a liberação de crédito no Fungetur e o Selo Turismo Responsável, mas a EMBRATUR segue com ações difusas e não coordenadas.

\title{
2.1. Trajetória do turismo Brasileiro - do Fordismo ao Turismo Competitivo
}

No Brasil, o turismo passou a ser visto como elemento passível de política pública na Era Vargas (1930-1945) quando, em 1939, foi criada a Divisão de Turismo dentro do Departamento de Imprensa e Propaganda da Presidência da República - DNIP tendo como objetivo “[...]organizar planos de propaganda no exterior e executá-los, organizar fichários e cadastro de informações turísticas, corresponder-se (sic) com outras organizações no plano internacional, organizar e divulgar material de propaganda turística sobre o país" (Santos Filho,

\footnotetext{
${ }^{1}$ En principio, se puede afirmar que la política turística es la actuación de la acción pública en relación con el turismo. Esto implica aquello que el gobierno decide hacer o no hacer en relación específica con el sector. Se hace hincapié en el término "específica» para diferenciar la política turística de otras, que pueden tener un impacto en el turismo, pero no se desarrollan como políticas turísticas en sí mismas. (Hall, 2010 como se cita en Schenkel, 2018).
} 
2008, p. 4). Em 1945 DNIP foi extinto e as questões do turismo deixaram a pauta das políticas públicas nacionais.

Em 1958 o Departamento de Turismo, durante o governo do presidente Juscelino Kubitschek, instituiu a Comissão Brasileira de Turismo - Combratur, vinculada diretamente à Presidência da República, com atribuições de coordenar, planejar e supervisionar a execução da Política Nacional de Turismo (Pimentel, M. P. et al., 2011, p. 12). As políticas apresentavam como foco a geração de divisas, aproveitamento do capital turístico brasileiro e expansão das atividades e serviços turísticos no país. De forma complementar, em 1961, criou-se a Divisão de Turismo e Certames no Ministério da Indústria e do Comércio com a responsabilidade de estimular o desenvolvimento do turismo interno e criação da Política Nacional de Turismo, mas em 1962 tanto a Combratur quanto a Divisão de Turismo e Certames foram extintas.

Após mais uma interrupção na estruturação da organização do turismo brasileiro, em 1966 cria-se, subordinada ao Ministério da Indústria, a EMBRATUR - Empresa Brasileira de Turismo e instituem-se o Conselho Nacional de Turismo (CNT), o Sistema Nacional de Turismo e o Fundo Geral do Turismo - Fungetur, na tentativa de estabelecer a Política Nacional de Turismo (Brasil, 1966). Este esforço concentrado ocorre durante a ditadura civil-militar tendo como objetivo a coordenação e a adaptação de todas as iniciativas, públicas ou privadas, isoladas ou coordenadas, com as reais necessidades de desenvolvimento econômico-cultural (Pimentel, M. P. et al., 2011).

Neste contexto compete à EMBRATUR fomentar e financiar diretamente as iniciativas, planos, programas e projetos que visassem o desenvolvimento da indústria do turismo, estudar de forma sistemática e permanente o mercado turístico, a fim de contar com os dados necessários para um adequado controle técnico, organizar, promover e divulgar as atividades ligadas ao turismo.

Durante os governos militares a gestão da EMBRATUR centrou-se na estruturação do turismo nacional a partir de incentivos fiscais à hotelaria, alimentação e entretenimento, levando à criação do FUNGETIR - Fundo Geral do Turismo e, o Anuário Estatístico de Turismo (Agência Brasileira de Promoção Internacional do Turismo - EMBRATUR, 2016). A partir de 1972, iniciou-se um movimento voltado ao mercado internacional, tendo como marco o Rio de Janeiro como sede do $45^{\circ}$ Congresso da American Society of Travel Agents (ASTA) e posteriormente a articulação com as Embaixadas e participação em eventos internacionais.

Após a redemocratização, buscou-se a reestruturação da imagem da EMBRATUR culminando na alteração de sua natureza jurídica tornando-a Instituto Brasileiro de Turismo vinculada ao Ministério do Esporte e Turismo tendo como finalidade apoiar a formulação e 
coordenar a implementação da política nacional do turismo, como fator de desenvolvimento social e econômico a partir da ampliação do fluxo de turistas internacionais e domésticos (Brasil, 1991).

Com a criação do Ministério do Turismo (Brasil, 2003) fez-se possível repensar as atribuições e caminhos possibilitando à EMBRATUR a focar-se na promoção internacional e apoio à comercialização. Coube a estes órgãos, a criação e implementação das políticas públicas de turismo, em especial, a Política Nacional de Turismo (Brasil, 2008).

Em meio a pandemia, em 25 de maio de 2020, uma nova alteração na estrutura oficial da EMBRATUR a partir da substituição da natureza jurídica vigente para a de Agência Brasileira de Promoção Internacional do Turismo (Brasil, 2020d), visando maior autonomia, orçamento e contratações via CLT, ao invés de concursos públicos. Esse movimento é consonante com as estruturas de outros DMOs - Destination Marketing Offices do mundo.

Figura 1 - Sistematiza a trajetória da pauta do turismo no Estado brasileiro

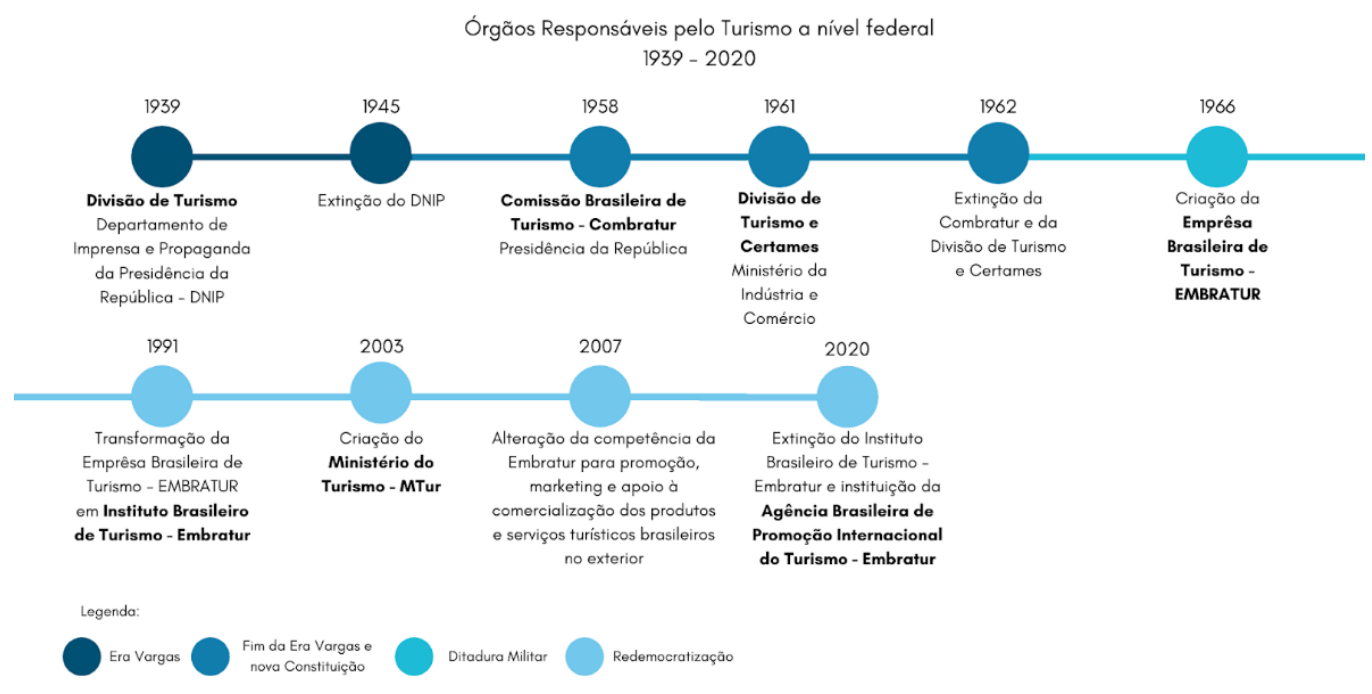

Fonte: Elaborado pelas autoras, 2020.

\section{METODOLOGIA}

A presente pesquisa tem caráter qualitativo e exploratório, com levantamento de documentos, pertencentes ao acervo do Centro de Excelência em Turismo (CET/UnB). Esses são: Plano de Promoção 1978/1979, da Coordenação de Marketing da EMBRATUR, Programa Brasil Turístico, campanha promocional apresentada aos conselheiros do CNTUR em 1983 e Estratégia para o Desenvolvimento do Turismo no Brasil, de novembro de 1990. A complementação da bibliografia foi realizada por meio de dissertações, monografias, 
documentos acessados nos sites do MTur e EMBRATUR, além de legislações e dados do Anuários Estatísticos do Turismo.

Adotou-se a Análise Documental dos planos, programas, projetos e ações de turismo encontrados. Essa metodologia é definida por Kelly (como citado em Cellard, 2012) pois permite a coleta de dados de forma direcionada impedindo ruídos em função da compreensão do pesquisador. Fez-se isso visando a objetividade e clareza das informações pesquisadas, evitando assim inconsistências na observação. Ainda assim, é válido observar que nos documentos, principalmente naqueles confeccionados em período de ditadura civil-militar, há sempre um tanto de influência de quem os redigiu, apresentando-se de forma clara ou não.

Por fim, a pesquisa avaliativa e análise de conteúdo, a partir do entendimento de Vasconcelos (2002, p. 161-169), com o intuito de validar os dados e informações coletados, de forma a fazer melhor juízo sobre o mérito e valor dos mesmos. Assim, se torna possível encontrar as relações existentes entre os diferentes componentes, nesse caso, dos documentos pesquisados.

A coleta documental foi realizada entre janeiro e maio de 2020, a mesma foi limitada em decorrência da pandemia de Covid-19, que impediu o acesso ao acervo do CET/UnB, limitando a pesquisa à documentos encontrados na internet, principalmente via SIC - Serviço de Informação ao Cidadão. Os principais achados foram documentos inéditos que nortearam a política da EMBRATUR nos anos 70 e 80 e a discussão interna acerca da nova Marca Brasil, ocorrida no ano de 2019.

\section{DISCUSSÕES E RESULTADOS}

A preocupação com o acompanhamento estatístico do fluxo de turistas estrangeiros que visitam o Brasil desde a década de 70 demonstra sua relação com o planejamento e gestão federal das políticas públicas de turismo, em especial as relacionadas à promoção, divulgação e apoio à comercialização. Portanto, faz-se necessário refletir sobre este monitoramento a partir do Gráfico 1. Ressalta-se que para os anos de 1968 e 1969 não foram localizados os dados nem relatos de períodos sem realização da pesquisa. 
Gráfico 1 - Relação de chegadas de turistas ao Brasil por ano, em milhões

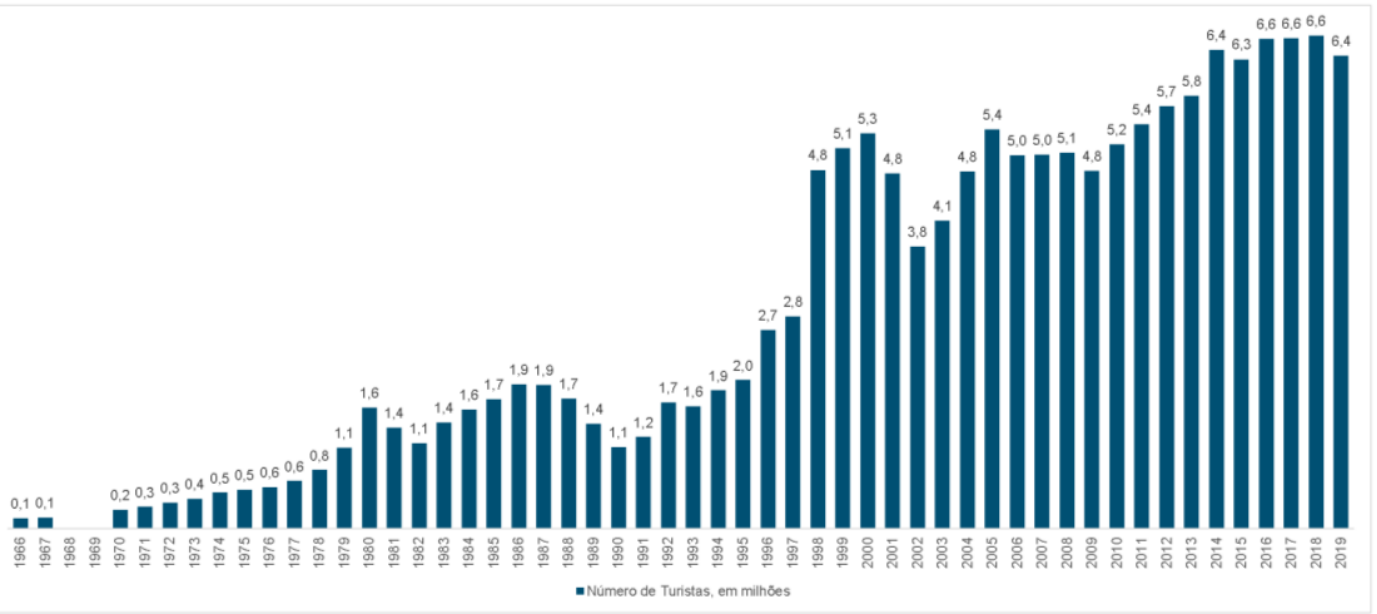

Fonte: Elaborado pelas autoras a partir dos Anuários Estatísticos de Turismo de 2005 a 2019 e Rose (1994, p. 14).

Atualmente o foco das políticas públicas de turismo, especialmente dos Planos Nacionais, mantêm como estratégia prioritária a ampliação de chegada de turistas estrangeiros, seja por refletir a efetividade das ações realizadas fara fomentar o mercado internacional quanto para viabilizar melhorias na balança comercial na expectativa de melhores desempenho. Para 2020 espera-se receber 12 milhões de turistas (Brasil, 2019).

Certamente esse cenário será comprometido pela pandemia de COVID-19, tanto para o turismo receptivo quanto para o emissivo. Além deste fato, observa-se pela evolução das chegadas de turistas que esta meta não reflete uma previsão possível, uma vez que nosso maior fluxo equivaleu a 6,6 milhões (2016-2018) e, em 2019, já apresentamos queda. Historicamente o crescimento quantitativo mais expressivo de entradas não ultrapassou 70\% entre 1997 e 1999.

\subsection{Efeitos das políticas públicas de turismo inspirados pela proposta de Pimentel, M. P. (et al., 2011)}

Ao considerar como recorte a atuação institucional da EMBRATUR na promoção de políticas públicas de turismo, sugere-se como estruturação das mesmas, em especial das estratégias de promoção em três períodos, considerando as conjunturas políticas e econômicas internas e externas, além da função do órgão e sua natureza: 1966 a 1984 - Ditadura CivilMilitar; 1985 a 2002 - da redemocratização a criação do MTur; 2003 a 2020 - da competência de promoção, marketing e apoio à comercialização dos produtos e serviços turísticos brasileiros no exterior aos dias atuais. Essa divisão é feita para melhor entendimento do contraste entre governos e políticas. 


\subsubsection{Ditadura Civil-Militar - 1966 a 1984}

Pode-se considerar que nesse período houve um direcionamento da promoção para propagar uma imagem de país que dialogava com a narrativa da ditadura civil-militar, como lugar próspero e tranquilo. Assim, o Plano de Promoção 1978/1979 e a campanha promocional apresentada aos conselheiros do CNTUR em 1983 possuem, entre si, as similaridades de tal narrativa. Vale ressaltar que nessa época a então empresa era responsável por todas as políticas públicas de turismo a nível federal, ou seja, internas e externas. Destaca-se que entre 1967 e 1971priorizou-se a estruturação do órgão e ações de incentivo fiscal para estímulo a criação de infraestrutura (EMBRATUR, 2016).

A gestão de Said Farhat (1975-1979), a participação do trade nacional em eventos fora do Brasil, como estratégia de promoção internacional e implementou o atendimento turistas estrangeiros que chegavam ao Brasil em voos fretados, com o uso de roteiros programados, cabendo este suporte à divisão de turismo do Ministério das Relações Exteriores

O documento Plano de Promoção 1978/1979 apresenta como meta “(...) manter a faixa de crescimento do turismo externo de $15 \%$ a $20 \%$ ao ano. Para o turismo interno, pretenderíamos manter os $20 \%$ atuais, porém crescendo para alguns polos em $30 \%$ (exemplo Norte-Nordeste e Centro-oeste)" (EMBRATUR, 1977). O objetivo básico das campanhas seria de fortalecer o processo comercial do produto brasileiro e integrar-se de forma global ao grande objetivo da política de marketing, utilizando uma comunicação de alto desempenho para conduzir o maior número possível de pessoas à decisão de fazer turismo no Brasil.

$\mathrm{O}$ foco das campanhas se deu em cinco mercados principais: 1. Estados Unidos e Canadá; 2. Alemanha; 3. França; 4. América Latina; e 5. Japão. Com exceção do Japão, os outros mercados já eram prioritários para a EMBRATUR. As formas de divulgação foram participação em eventos, distribuição de brochuras e folhetos contendo as informações "onde ir", "o que ver" e "como chegar lá" e mala direta com materiais promocionais específicos.

Um aspecto que deve ser ressaltado é que a estratégia de promoção do período criou um imaginário internacional sobre o país que ainda persiste em muitos locais, ressaltando praias, manifestações culturais, alimentos típicos e, de forma sexualizada, a mulher brasileira. Nesse aspecto, Alfonso (2006, p. 88) destaca que

O uso da imagem da mulher brasileira vinculada aos festejos carnavalescos não se restringia apenas à publicidade da EMBRATUR. No mesmo período, a revista Rio, Samba e Carnaval, distribuída em vários idiomas no Brasil e no exterior, com o apoio da EMBRATUR, usava e abusava da imagem da mulher como o principal atrativo turístico do Rio de Janeiro. 
As Figuras 2 e 3 exemplificam estas ações:

Figura 2 - Mulher, revista Rio, Samba e Carnaval de 1973 Figura 3 - Brazil tour guide 1977

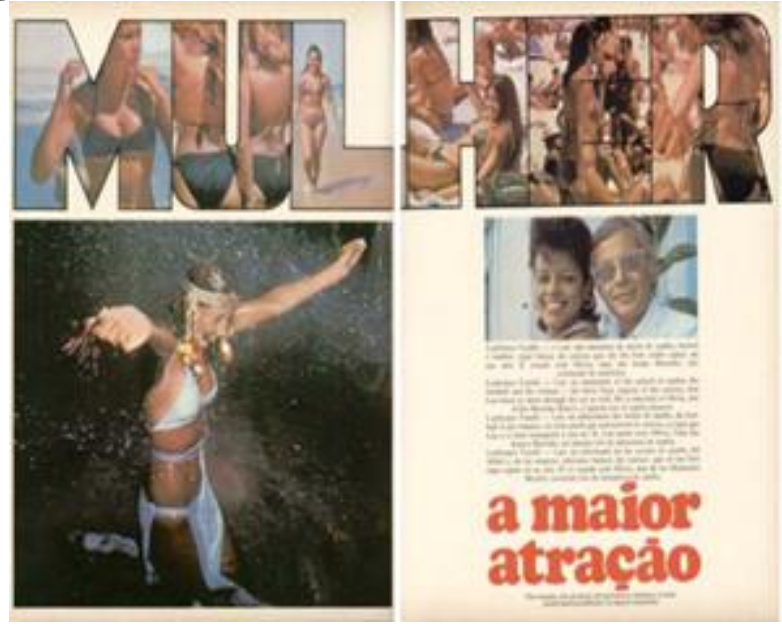

Fonte: Alfonso, 2006, p. 89

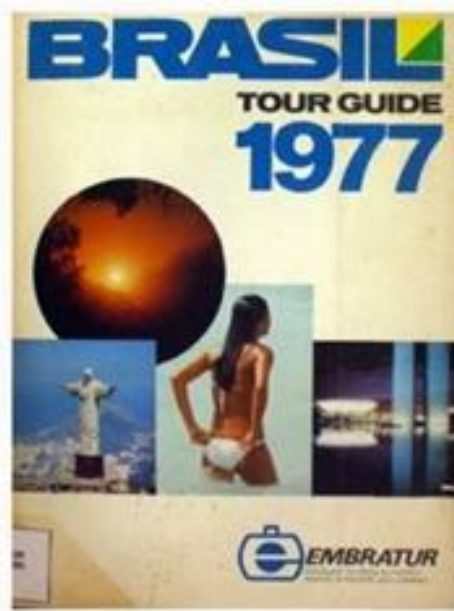

Fonte: EMBRATUR, 1977.

Miguel Colasuonno (1979-1984) deu continuidade à esta estratégia, implantando escritórios de promoção em Nova York, Frankfurt e Paris. Além disso, foram lançados diversos programas de incentivo para viagens ao Nordeste e Norte, inclusive com financiamento de viagens de estrangeiros à juros subsidiados e um bilhete que permitia ao turista estrangeiro viajar por três semanas sem limite de quilometragem em qualquer voo doméstico (EMBRATUR, 2016). Durante sua gestão como Presidente da EMBRATUR, Colasuonno implementa o Programa Brasil Turístico (EMBRATUR, 1983). Esta foi uma campanha promocional, direcionada aos públicos $\mathrm{A}$ e $\mathrm{B}$, na qual destacava-se as paisagens naturais e românticas (imagens 3 e 4). A campanha incentivava que o turista comprasse de alguns prestadores de serviços específicos, como a Agência Geral e o Bradesco Turismo, além de ressaltar que o Banco Real apoiava o desenvolvimento do turismo brasileiro.

Nesse período, haviam sido criadas novas leis e decretos, que determinavam áreas especiais e locais de interesse turístico no país (Brasil, 1977) e obrigavam o registro das empresas exploradoras de atividades turísticas junto à EMBRATUR (Brasil, 1967). 
Figura 4 - Viagem, o Brasil tem quilômetros de montanhas tão bonitas quanto as praias. E vice-versa e Nada como uma viagem pelo Brasil para você descobrir do que a

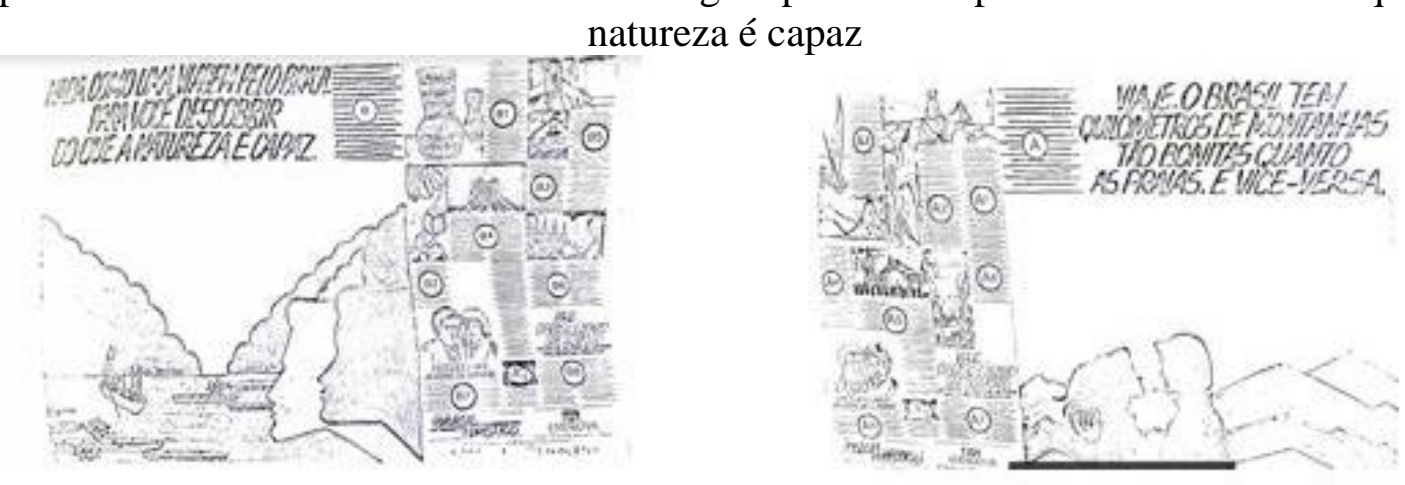

Fonte: EMBRATUR, 1983.

Gian Luigi de Rosa (2013, p. 21, tradução nossa) ${ }^{2}$ ressalta que a

\begin{abstract}
Embratur queria especificamente criar uma imagem turística do Brasil que pudesse promover o turismo de massa, assim como melhorar a imagem país no panorama internacional. De fato, de 1964 a 1984, o governo brasileiro foi fortemente criticado por estudantes expatriados e sindicalistas, assim como pela imprensa internacional, por seu regime ditatorial e ferozes crimes políticos, que incluíam o desaparecimento de oponentes políticos. Porém, a Embratur nunca admitiu oficialmente as metas supracitadas (...).
\end{abstract}

Apesar das contradições das gestões durante o período de ditatura, o autor destaca que internacionalmente as ações garantiram o sombreamento da violência do período ditatorial brasileiro (Rosa, 2013). Aliada a esta percepção, observa-se que durante esta fase o fluxo turístico internacional cresceu acumuladamente $1099,79 \%$. O custo deste crescimento ainda está refletido na imagem equivocada da mulher brasileira.

\title{
4.1.2. Da redemocratização a criação do Ministério do Turismo - 1985 a 2002
}

O ano de 1985 ficou marcado, no Brasil, pelo início da redemocratização. Pela primeira vez desde 1964 o país teve um presidente civil - José Sarney (vice de Tancredo Neves, que faleceu antes de tomar posse), apesar do mesmo não ter sido eleito por voto direto.

Esse período foi de grandes mudanças na natureza e competências da EMBRATUR que, em 1991, deixou de ser uma empresa estatal para se tornar o Instituto Brasileiro de Turismo, agregando em suas competências a função de formular, coordenar, executar e fazer executar a Política Nacional de Turismo.

\footnotetext{
${ }^{2}$ Embratur specifically wanted to create a tourist image of Brazil which could promote mass tourism, as well as improve the image of the Country on the international panorama. Indeed, from 1964 to 1984, the Brazilian government was strongly criticised by expatriate scholars and trade unionists, as well as by the international press, for its dictatorial regime and ferocious political crimes which included the disappearance of political opponents (desaparecidos). However, Embratur never officially admitted having the above-mentioned aims (...).
} 
Em meio à crise econômica deixada como herança da ditadura civil-militar e os problemas orçamentários, faltaram campanhas e ações relativas ao produto turístico nacional. De acordo com Alfonso (2006) a Gestão de Joaquim de Castro (1985-1986) concentrou-se na revisão das estratégias institucionais e redução dos custos a partir da redução do quadro de colaboradores e de custeio de matérias e patrimônios, encerramento das atividades de escritórios no exterior. Estas ações garantiram superávit financeiro à Empresa.

A partir da gestão Joaquim de Castro (1985-1986), o foco institucional retorna ao marketing turístico e ao mercado. Em 1987 Pelé torna-se "Embaixador do Turismo Brasileiro", e utilizar sua imagem em campanhas publicitárias ao redor do mundo, com os dizeres "Emotion has a name: Brazil"33 (Kajihara, 2010, p. 13). Apesar da tentativa de ressignificação da imagem do Brasil, manteve-se a veiculação de propagandas com imagens femininas (Figura 5).

Figura 5 - Boletim de Imprensa No 18 - Dezembro 87 - EMBRATUR

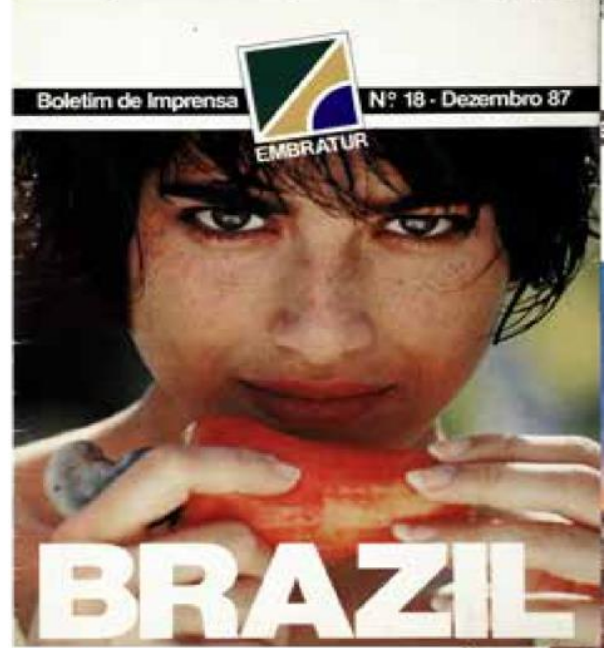

Fonte: EMBRATUR, 2016.

As ações mais relevantes do período, no que concerne à promoção internacional, foram: divulgação do país como destino turístico nos Estados Unidos, junto à empresas privadas; Investimento de 500.000,00 dólares - R \$ 1.895.000,00 em valores atuais (Ipeadata, 2020) para divulgação do Brasil na Europa; Reabertura do escritório da EMBRATUR em Nova York e abertura de escritório da França; Criação do Programa de Desenvolvimento do Turismo Prodetur, nas regiões Nordeste e Sul; e Instalação de comitês "Visite o Brasil" nos Estados Unidos, Inglaterra, Argentina, Itália e França. (EMBRATUR, 2016).

Durante a gestão de Ronaldo do Monte Rosa (1990-1992), apresentou-se o plano “Estratégia para o desenvolvimento do turismo no Brasil" (EMBRATUR, 1990), reafirmando

\footnotetext{
${ }^{3}$ Emoção tem um nome: Brasil, em tradução livre.
} 
a importância econômica do setor no Brasil e no mundo, o produto turístico do país, o papel do marketing no desenvolvimento do mercado brasileiro e a ação do governo e apresentando as perspectivas para os setores de hospedagem, fluxo de receptivo e interno, recursos para investimentos e ações de marketing. Por fim, são propostas as estratégias de ação, seus programas e metas.

É visível que a EMBRATUR começa a dar atenção à competitividade em relação aos outros mercados receptores de turismo e às estatísticas do país, apontando, inclusive, fatores externos como o câmbio de outros países e suas influências na entrada de turistas estrangeiros no Brasil. Muitos dos apontamentos têm como fonte sua Divisão de Estatística.

As estratégias de ação propostas foram: Aumento da eficiência e ampliação da capacidade instalada, democratização do acesso ao turismo, política agressiva de marketing, diversificação da oferta turística, formação de recursos humanos e desregulamentação da expansão das atividades turísticas. Assim, previu-se implantação de polos turísticos com financiamento de meios de hospedagem, adequação de infraestrutura para turismo ecológico e interiorização do fluxo turístico, focando nos destinos Costa do Sol (PB), Costa Dourada (PE/AL), Amazônia e Pantanal.

No tocante da ressignificação da imagem do Brasil, é proposto como meta a "Promoção através de campanhas publicitárias" (EMBRATUR, 1990, p. 24-25), os principais pontos abordados foram:

a) Nova imagem do Brasil no Exterior, direcionado aos principais mercados emissores, visando restituir a confiança e o interesse do turista com respeito ao produto turístico nacional; b) Turismo Ecológico, direcionado a estimular as viagens justamente com a valorização e proteção do patrimônio natural. O movimento ecológico está motivando um número crescente de pessoas a relevar o conforto em favor do convívio com a natureza, tornando, dessa forma, o turismo ecológico um dos mais comercializáveis; c) Campanhas de oportunidade que, revestindo-se de características muito particulares, valendo-se de eventos ocasionais e/ou de promoções de maior repercussão nacional ou internacional, atuam com apresentação de temário e material promocional versátil suscitado pela presença de um público com finalidade específica.

Segue abaixo gráfico comparando as expectativas da EMBRATUR e os números reais da chegada de turistas no Brasil entre 1991 e 1994. Destaca-se que a meta de ampliação do fluxo de turistas previsto só foi alcançada em 1998. 
Gráfico 2 - Projeção da EMBRATUR em 1990 versus o número de turistas recebidos nos mesmos anos

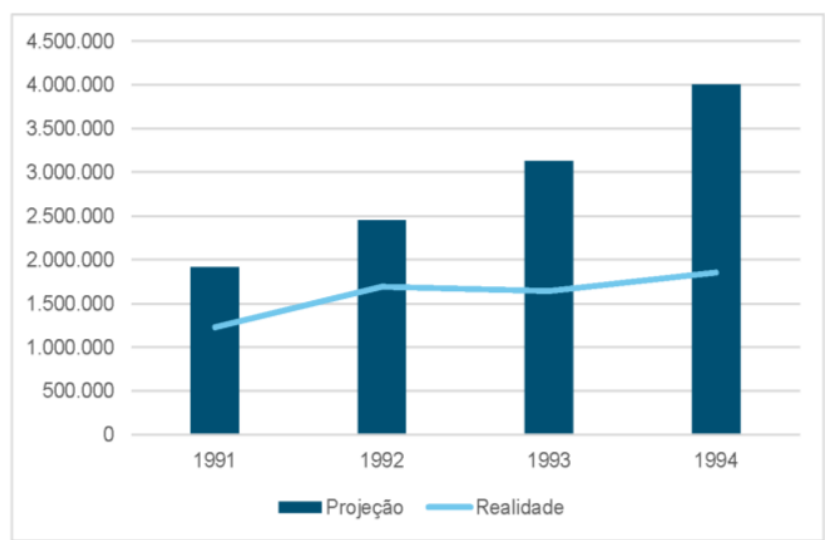

Fonte: Elaborado pelas autoras com base em dados da EMBRATUR (1990) e do livro Turismo: Planejamento e Marketing (Rose, 1994, p. 14).

Assim, no período compreendido entre janeiro de 1985 e dezembro de 2002, o Brasil recebeu 47.553.587 turistas, no total. O ano de 1998 apresentou o maior aumento relativo, de 69,07\% em relação à 1997. Ainda nesse sentido, 1990 apresentou a maior queda, recebendo $22,23 \%$ turistas a menos do que o ano anterior.

\subsubsection{Da promoção, marketing e apoio à comercialização dos produtos $\mathrm{e}$} serviços turísticos brasileiros no exterior à busca por fomento - 2003 a 2020

Em 2003, no início do mandato do presidente Lula, a Lei no 10.683, de 28 de maio de 2003, determinou a criação do Ministério do Turismo, tornando a EMBRATUR uma autarquia e dividindo suas competências com o mesmo. Coube à EMBRATUR "a promoção, marketing e o apoio à comercialização do produto turístico brasileiro no mundo" (Brasil, 2003).

Neste contexto, Eduardo Sanovicz (2003-2006) prioriza a elaboração e lançamento do plano de marketing turístico internacional "Aquarela do Brasil" (EMBRATUR, 2005), sob consultoria da Chias Marketing. Nele, inventariou-se os atrativos culturais e naturais, a infraestrutura geral e os equipamentos turísticos. Inclusive, apresenta-se um estudo de tendências com previsão de chegada de turistas (Imagem 6):

Figura 6 - Tendências do Turismo Mundial, OMT, 2004

\begin{tabular}{|l|r|r|r|r|r|r|}
\cline { 2 - 7 } \multicolumn{1}{c|}{} & 1990 & 1995 & 2002 & 2003 & $\begin{array}{r}\text { Previsảo } \\
2010\end{array}$ & $\begin{array}{r}\text { Previsāo } \\
2020\end{array}$ \\
\hline MUNDO & 457,2 & 565,4 & 714,6 & 694 & $1.006,0$ & $1.561,0$ \\
\hline AMÉRICAS & 92,8 & 108,9 & 120,0 & 112,4 & 190,0 & 282,0 \\
\hline AMÉRICA DO SUL & 7,9 & 11,8 & 12,5 & 9,3 & 26,9 & 42,8 \\
\hline BRASIL & 1,09 & 1,99 & 3,78 & 4,09 & 9,0 & 14,1 \\
\hline
\end{tabular}

Fonte: EMBRATUR, 2005. 
O plano apresenta um estudo aprofundado da realidade do turismo nacional, do uso do produto turístico e o perfil do turista internacional. Assim, chega-se à discussão acerca da marca país. De acordo com o documento, “o Brasil não adotou na história da sua trajetória turística uma marca”. A descontinuidade foi observada tanto na utilização de símbolos quanto de logomarcas. (EMBRATUR, 2005). Assim, se reforça a necessidade da construção de identidade da promoção baseada em uma marca e uma mensagem global que oriente a visão a ser passada. Isso não havia sido aplicado pelo Brasil até então, como é evidenciado na imagem a seguir:

Figura 7 - Uso da imagem do Brasil pela EMBRATUR

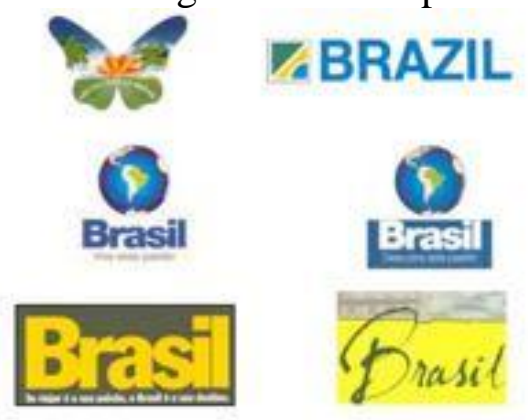

Fonte: EMBRATUR, 2005, p. 65

Entendendo a relevância do posicionamento da imagem do país em termos de produto turístico internacional, elege-se como marca um símbolo que potencialize o patrimônio natural e o estilo de vida brasileiro, sintetizando os valores da cultura nacional (Natureza; Cultura viva; Povo; Clima; e Modernidade) e o slogan “Sensacional” (EMBRATUR, 2005).

Figura 8 - Marca Brasil, proposta pelo designer Kiko Farias e utilizada pela EMBRATUR entre 2005 e 2019

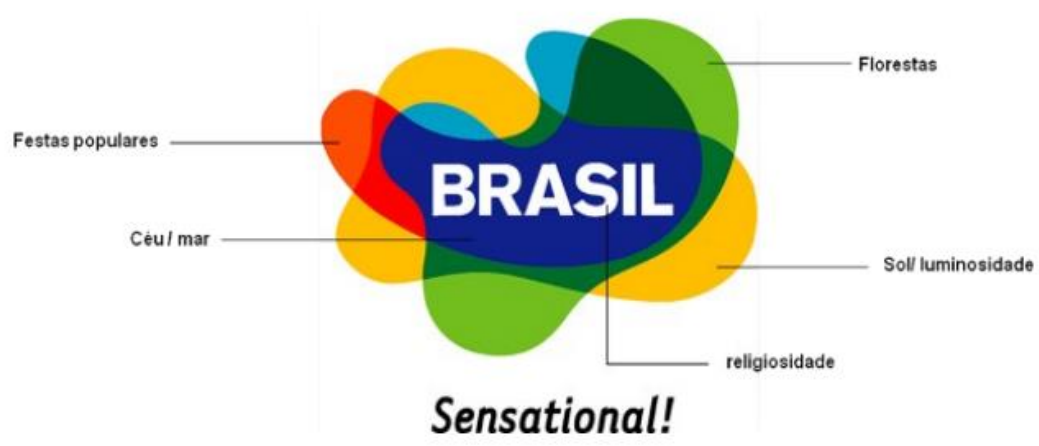

Fonte: EMBRATUR, 2007, p. 52.

A partir do lançamento do Plano Aquarela, a EMBRATUR começou a trabalhar sistematicamente com a oferta de 5 produtos: Sol e Praia, Ecoturismo, Cultura, Esporte e 
Negócios \& Eventos. Dentro desses, havia subprodutos e, para cada um, argumentos de promoção. No geral, os apelos eram: Natureza, cultura viva, povo, clima e modernidade. Nele são propostas as ações em relação a cada segmento. Para reforçar a divulgação, foram criados oito Escritórios Brasileiros de Turismo (EBT) em mercados prioritários: Portugal, Espanha, Itália, França, Alemanha, Inglaterra, Estados Unidos e América do Sul.

A partir da confirmação do Brasil como país cede da Copa do Mundo FIFA de 2014 e o Rio de Janeiro como sede dos Jogos Olímpicos de 2016, os esforços de promoção são direcionados ao apoio à criação da identidade visual destes megaeventos. Isso fica claro quando são apresentados os objetivos da promoção internacional "contribuir para o sucesso da Copa do Mundo e dos Jogos Olímpicos; maximizar os resultados para o turismo brasileiro; otimizar a exposição mundial do país para torná-lo mais conhecido" (EMBRATUR, 2009).

Em sínteses, entre 2003 e 2016, os principais feitos do órgão foram: abertura dos Escritórios Brasileiros de Turismo no Exterior, campanha “Brasil. Quem conhece vira fã!", criação da Marca Brasil, formação online de agentes de viagens do exterior que trabalhavam com o destino Brasil, instituição da Inteligência de Mercado, realização de roadshows e workshops para promoção do produto turístico brasileiro, entre outros (EMBRATUR 50 Anos - Uma trajetória do turismo no Brasil, 2016).

Pode-se considerar que o Plano Aquarela é a política pública de maior continuidade do órgão, já que possui edições que abarcam desde o ano de 2003 até 2020 (lançado em 2009). A Marca Brasil só foi descontinuada no ano de 2019. Assim, no momento da consolidação dessa política, houve um salto no número de turistas recebidos pelo país.

A partir de 2019, observa-se a ruptura na promoção turística internacional a partir do lançamento do Plano Aquarela 2020, com a apresentação de uma nova marca país, com os dizeres "Brazil, visit and love us"4 (imagem 9), que representa um "(...) convite aos visitantes se encantarem com o Brasil, para que eles aproveitem tudo o que de melhor podemos oferecer" (EMBRATUR, 2019). E, a escolha da bandeira nacional como símbolo da promoção turística, foi feita para representar as riquezas naturais, culturais e sociais a partir do símbolo máximo da nação.

\footnotetext{
${ }^{4}$ Brasil, visite e nos ame, em tradução livre.
} 


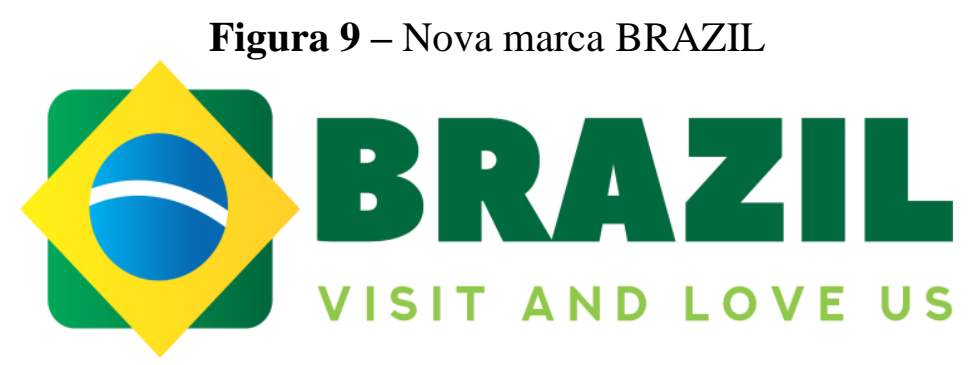

Fonte: EMBRATUR, 2019.

Apesar de tal justificativa, um documento obtido pela Lei de Acesso à Informação -

LAI, mostra que a mudança teve objeção dentro do próprio órgão. No trâmite do Ofício 121/2019/PRESI-EMBRATUR de 13 de junho de 2019, dentro do processo SEI 72100.001026/2019-76, técnicos da Coordenação-Geral de Marketing Digital da EMBRATUR se posicionaram de forma contrária à mudança, argumentando que:

\begin{abstract}
(...) o conhecimento da Marca Brasil cresceu de 11\% para 20\% (entre 2006 e 2009), nível alto quando consideramos o pouco tempo desde sua implantação. As principais sensações associadas à marca são: brilhante e colorida, brasileira, alegre, natural." (Plano Aquarela, 2020, página 35). 3) Valor de mercado da Marca Brasil - A Marca Brasil, desde sua criação em 2004, foi sempre vinculada a qualquer esforço de comunicação feito pela Embratur para a promoção do turismo internacional. De fato, no Estudo de demanda turística internacional realizado pelo Ministério do Turismo anualmente, foi constatado que $34,6 \%$ dos turistas entrevistados identificaram a Marca Brasil (Fonte: Pesquisa de Caracterização e Dimensionamento do Turismo Internacional no Brasil 2018.) A Marca, quando restringida a análise de sua percepção ao trade turístico internacional, possui reconhecimento e relevância, sendo constante a demanda de parceiros nacionais públicos e privados e empresas ou instituições do trade internacional que solicitam a utilização da Marca Brasil em seus materiais e websites (SEI 72100.001026/2019-76 / p. 43 como citado em Santos, 2020, p. 48).
\end{abstract}

Assim, a viabilidade da nova marca BRAZIL é questionada no sentido de que, a produção de materiais solicitada pelo órgão “(...) em sua maioria não se trata efetivamente de esforço de comunicação promocional para o público internacional, mas de produtos de uso interno da entidade, afetando tão somente colaboradores e público nacional”. Além disso, o corpo técnico solicita que haja pesquisa antes da alteração da marca país.

Para Jeanine Pires, ex-presidente do órgão, podem ser elencados cinco motivos de retrocesso em relação à nova marca: (1) grafia do nome do país, apresentada com Z; (2) o custo já desprendido pelo poder público no reposicionamento da marca; (3) erro de interpretação na leitura do "US" por ser também a sigla dos Estados; reaproximação com a conotação sexual, visto histórico de propagandas dos anos 1970 e 1980, a partir do uso da palavra "LOVE", (5) a logo, por si só, não é relevante em termos de posicionamento de mercado (Pires, 2019).

\footnotetext{
5 "Nós" em tradução livre

${ }^{6}$ Amor, em tradução livre
} 
Em 2020, foi sancionada a Lei 14.002 que cria Agência Brasileira de Promoção Internacional do Turismo - EMBRATUR, tendo como competência planejar, formular e implementar serviços turísticos. Seu diferencial concentra-se na possibilidade de captação de recursos não estatais.

\section{CONSIDERAÇÕES FINAIS}

Foram diversas as transformações da EMBRATUR em seus 56 anos de existência. Houve momentos em que as políticas do órgão não eram claras, em outros, dentro de suas limitações, foram transformadoras para o turismo nacional. O objetivo deste artigo foi analisar as estratégias de promoção do Brasil no exterior a partir do mapeamento dos planos, programas e ações realizados pela Agência Brasileira de Promoção Internacional do Turismo (EMBRATUR). Destaca-se que a fundação da Empresa Brasileira de Turismo se deu em um período no qual seus objetivos eram muito mais de construção de imagem específica do Brasil do que de captação de turistas internacionais. Nessa época, foram cometidos erros que ainda repercutem atualmente, principalmente em relação à mulher brasileira. Ainda, há uma preocupação em relação às reais intenções por trás da sua fundação, visto que ocorreu em meio à ditadura civil-militar.

Depois, foram muitas as ações tomadas, mas sem planos nacionais propostos. $\mathrm{O}$ órgão foi o único responsável pelo turismo brasileiro a nível nacional por quase 40 anos e, nesse tempo, por muitas vezes não houve um movimento de profissionalização do serviço prestado. Assim, parte de sua história se baseia em tentativas isoladas e sem continuidade de ordenar o turismo nacional.

A criação do Ministério do Turismo, em 2003, pode ser considerada um divisor de águas para a história do órgão. Foi a partir da mesma que a EMBRATUR começou a ter planos, programas, ações e projetos com continuidade, cumprindo seu papel como formuladora de políticas públicas e tendo um foco mais definido. A Marca Brasil acompanhou esse processo de profissionalização do órgão, tendo sido substituída de forma abrupta em 2019, sem razão clara.

Por fim, a EMBRATUR passou por diversas mudanças de natureza. No momento em que este artigo se encerra, ela começa uma nova trajetória como Agência Brasileira de Promoção Internacional do Turismo, caminho que traz grandes expectativas ao país. Espera-se que haja a gestão necessária para entender a trajetória da Agência e, compreendendo o sistema à sua volta, posicioná-la de forma a aproveitar ao máximo os recursos turísticos nacionais, utilizando-se de métodos inovadores e evitando repetir os erros passados. 


\section{REFERÊNCIAS}

Agência Brasileira de Promoção Internacional do Turismo - EMBRATUR. (1977). Plano de Promoção 1978-1979. Brasília, DF.

Agência Brasileira de Promoção Internacional do Turismo - EMBRATUR. (1983). Programa Brasil Turístico. Rio de Janeiro: Alcântara Machado Periscinoto Comunicações Ltda.

Agência Brasileira de Promoção Internacional do Turismo - EMBRATUR. (1990). Estratégia para o desenvolvimento do turismo no Brasil. Brasília, DF.

Agência Brasileira de Promoção Internacional do Turismo - EMBRATUR. (2005). Plano Aquarela do Brasil - Marketing Turístico Internacional do Brasil. Brasília, DF.

Agência Brasileira de Promoção Internacional do Turismo - EMBRATUR. (2007). Plano Aquarela - Marketing Turístico Internacional do Brasil - 2007-2010. Recuperado em 24, agosto, 2020, de

http://www.turismo.gov.br/sites/default/turismo/o_ministerio/publicacoes/downloads_publica coes/Plano_Aquarela_2007_a_2010.pdf

Agência Brasileira de Promoção Internacional do Turismo - EMBRATUR. (2009). Plano Aquarela 2020 - Marketing Turístico Internacional do Brasil. Recuperado em 24, agosto, 2020, de

http://www.embratur.gov.br/lai_embratur_secom/export/sites/lai/galerias/download/Plano_Aq uarela_2020.pdf

Agência Brasileira de Promoção Internacional do Turismo - EMBRATUR. (2016).

EMBRATUR 50 anos, uma trajetória do turismo no Brasil. Brasília, DF.

Agência Brasileira de Promoção Internacional do Turismo - EMBRATUR. (2019). Embratur desenvolve nova marca para promoção internacional. Recuperado em 24, agosto, 2020, de http://www.embratur.gov.br/piembratur-

new/opencms/salaImprensa/noticias/arquivos/Embratur_desenvolve_nova_marca_para_prom ocao_internacional_.html

Alfonso, L. P. (2006). EMBRATUR Formadora de Imagens da Nação Brasileira. São Paulo: Annablume.

Brasil. Decreto-lei $n^{\circ} 55$, de 18 de Novembro de 1966. (1966). Define a política nacional de turismo, cria o Conselho Nacional de Turismo e a Emprêsa Brasileira de Turismo, e dá outras providências. Brasília, DF. Recuperado de http://www.planalto.gov.br/ccivil_03/decretolei/1965-

1988/Del0055.htm\#: :text=Define\%20a\%20pol\%C3\%ADtica\%20nacional\%20de,Turismo\% $2 \mathrm{C} \% 20 \mathrm{e} \% 20 \mathrm{~d} \% \mathrm{C} 3 \% \mathrm{~A} 1 \% 20$ outras $\% 20$ provid $\% \mathrm{C} 3 \%$ AAncias.$\&$ text $=$ Art. $\&$ text $=4 \% \mathrm{C} 2 \% \mathrm{BA}$ $\% 20 \%$ C3\%89\%20criado\%20o\%20Conselho,a\%20pol\%C3\%ADtica\%20na

Brasil. Decreto $n^{\circ}$ 60.224, de 16 de fevereiro de 1967. (1967). Regulamenta o Decreto-lei $\mathrm{n}^{\circ}$ 55 , de 18 de novembro de 1966. Brasília, DF. Recuperado de https://www2.camara.leg.br/legin/fed/decret/1960-1969/decreto-60224-16-fevereiro-1967400926-norma-pe.html 
Brasil. Lei $n^{\circ} 13.979$, de 6 de Fevereiro de 2020. (2020a). Dispõe sobre as medidas para enfrentamento da emergência de saúde pública de importância internacional decorrente do coronavírus responsável pelo surto de 2019. Diário Oficial da União. Brasília, DF.

Brasil. Lei $n^{\circ}$ 14.035, de de 11 de Agosto de 2020. (2020b). Altera a Lei $\mathrm{n}^{\circ}$ 13.979, de 6 de fevereiro de 2020, para dispor sobre procedimentos para a aquisição ou contratação de bens, serviços e insumos destinados ao enfrentamento da emergência de saúde pública de importância internacional decorrente do coronavírus responsável pelo surto de 2019. Câmara dos Deputados - Palácio do Congresso Nacional - Praça dos Três Poderes. Brasília: DF.

Brasil. Lei $n^{\circ} 6.513$ de 20 de dezembro de 1977. (1977). Dispõe sobre a criação de Áreas Especiais e de Locais de Interesse Turístico; sobre o Inventário com finalidades turísticas dos bens de valor cultural e natural. Brasília, DF. Recuperado de http://www.planalto.gov.br/ccivil_03/leis/16513.htm

Brasil. Lei $n^{\circ}$ 8.181, de 28 de março de 1991. (1991). Dá nova denominação à Empresa Brasileira de Turismo (Embratur), e dá outras providências. Revogado pela Lei $\mathrm{n}^{\circ} 14.002$, de 2020. Brasília, DF. Recuperado de http://www.planalto.gov.br/ccivil_03/leis/18181.htm

Brasil. Lei $n^{\circ} 10.683$, de 28 de maio de 2003. (2003). Dispõe sobre a organização da Presidência da República e dos Ministérios, e dá outras providências. Revogado pela Medida Provisória $\mathrm{n}^{\mathrm{o}} 782$, de 2017. Revogado pela Lei $\mathrm{n}^{\circ}$ 13.502, de 2017. Brasília, DF. Recuperado de http://www.planalto.gov.br/ccivil_03/leis/2003/110.683.htm

Brasil. Lei $n^{o} 11.771$, de 17 de setembro de 2008. (2008). Dispõe sobre a Política Nacional de Turismo, define as atribuições do Governo Federal no planejamento, desenvolvimento e estímulo ao setor turístico. Brasília, DF. Recuperado de http://www.planalto.gov.br/ccivil_03/_Ato2007-2010/2008/Lei/L11771.htm

Brasil. Lei $n^{\circ}$ 14.002, de 22 de maio de 2020. (2020d). Autoriza o Poder Executivo federal a instituir a Agência Brasileira de Promoção Internacional do Turismo (Embratur); extingue o Instituto Brasileiro de Turismo (Embratur); revoga a Lei no 8.181, de 28 de março de 1991; e dá outras providências. Brasília, DF. Recuperado de:

http://www.planalto.gov.br/ccivil_03/_Ato2019-

2022/2020/Lei/L14002.htm\#: :text=Altera\%20as\%20Leis\%20nos,agosto\%20de\%202011\%3 B\%20autoriza\%20o

Brasil. Ministério do Turismo. (2019). Plano Nacional do Turismo 2018-2022. Ministério do Turismo. Brasília, DF. Recuperado de http://www.turismo.gov.br/images/pdf/PNT_20182022.pdf

Brasil. Ministério do Turismo. (2020c). Não cancele, REMARQUE. Ministério do Turismo. Recuperado de http://antigo.turismo.gov.br/nao-cancele-remarque.html

Cellard, A. (2012). A Análise Documental. In: Poupart, J., Deslauriers, J. P., Groulx, L. H., Laperrière, A., Mayer, R., Pires, A., Jaccoud, M., Cellard, A., Houle, G., \& Giorgi, A. A pesquisa qualitativa: enfoques epistemológicos e metodológicos. Petrópolis: Vozes.

Covid-19 Visualizer. (s.d.). COVID-19. Recuperado de https://www.covidvisualizer.com/

Ipeadata. (2020). Taxa de câmbio comercial para compra: real (R\$) / dólar americano (US\$) - média. Recuperado em 14, agosto, 2020, de http://www.ipeadata.gov.br/ExibeSerie.aspx?serid=38590\&module=M 
Kajihara, K. A. (2010). A imagem do Brasil no exterior: Análise do material de divulgação oficial da EMBRATUR, desde 1966 até 2008. Revista Acadêmica Observatório de Inovação do Turismo, 2-30.

Lohmann, G., \& Panosso Netto, A. (2008). Teoria do Turismo: conceitos, modelos e sistemas. São Paulo: Aleph.

Panosso Netto, A., Oliveira, J. L. S., \& Severini, V. F. (2020). Do overtourism àestagnação. Reflexões sobre a pandemia do Coronavírus e o turismo. Cenário: Revista Interdisciplinar Em Turismo E Território, 8(14), 26-43.

Pimentel, M. P., Pereira, J. R., Pimentel, T., \& Carrieri, A. P. (2011). As Cinco Vidas da Agenda Pública Brasileira de Turismo. Revista Acadêmica Observatório de Inovação do Turismo, 1-25.

Pires, J. (2019). 5 motivos que mostram o retrocesso da nova Marca Brasil. MKT Destinos. Recuperado de https://blog.panrotas.com.br/mktdestinos/2019/07/17/5-motivos-que-mostramo-retrocesso-da-nova-marca-brasil/

Rosa, G. L. (2013). The development of the tourist imagery of Brazil: in between stereotypes and clichés. In: Manca, E., \& Bianchi, F. Tourism and tourist promotion around the world: a linguistic and socio-cultural perspective. Unisalento Press.

Rose, A. T. (1994). Turismo: planejamento e marketing: aplicação da matriz de portfólio para destinações turísticas. Manole.

Santos, P. S. (2020). "Bate Palmas com Vontade, Faz De Conta Que é Turista”: As Possibilidades da Política Pública de Turismo Sob a Ótica Da Nova Agência Brasileira de Promoção Internacional do Turismo (EMBRATUR). Trabalho de Conclusão de Curso em Turismo, Universidade de Brasília, Brasília, DF, Brasil.

Santos Filho, J. (2008). O Turismo na Era Vargas e o Departamento de Imprensa e Propaganda - DIP. Cultur: Revista de Cultura e Turismo, 102-115.

Schenkel, E. (2018). Turismo y política turística. Un análisis teórico desde la ciencia política. Universidad Nacional del Sur, Argentina. Consejo Nacional de Investigaciones Científicas y Técnicas (CONICET), Argentina. Recuperado de file:///C:/Users/pc/Downloads/34212Texto\%20del\%20art\%C3\%ADculo-126934-1-10-20190613.html

Souza, C. (2006). Políticas Públicas: Uma Revisão da Literatura. Sociologias (UFRGS), 2045.

Vasconcelos, E. M. (2002). Complexidade e Pesquisa Interdisciplinar: epistemologia e metodologia operativa. Petrópolis: Vozes.

FORMATO PARA CITAÇÃO DESTE ARTIGO

WIESINIESKI, L. C. B. S., \& SANTOS, P. S. (2021). A política pública de turismo da Embratur e suas transformações até a atualidade. Revista de Turismo Contemporâneo, 9(3), 363-384. https://doi.org/10.21680/2357-8211.2021v9n3ID23460 